\title{
Apuntes sobre el principio de responsabilidad en el Derecho constitucional europeo*
}

\author{
Enrique Guillén López \\ Profesor Titular de Derecho constitucional \\ Universidad de Granada
}

Recibido: 01.10.2012

Aceptado: 15.10.2012

\begin{abstract}
Resumen: La presente contribución pretende acercarse a las diferentes acepciones que tiene el principio de responsabilidad de los poderes públicos en la UE y en los Estados miembros. Se parte, así, de la esencialidad del principio de responsabilidad en los modelos constitucionales y de cómo se desgajan como instituciones separadas la responsabilidad política y la responsabilidad jurídica. La diferente lógica a la que responde cada forma de responsabilidad explica cómo sólo una vez alcanzada la responsabilidad jurídica puede alcanzarse la política en el seno de la UE. En especial, nos detendremos en el principio de responsabilidad patrimonial por infracción del derecho comunitario y en la forma en que puede suponer un aldabonazo al modelo de corrección de las situaciones creadas por la eventual inconstitucionalidad de la ley en los Estados miembros. Una acepción del principio de responsabilidad jurídica en la UE está suponiendo modificar el concepto de responsabilidad en los Estados miembros, y con ello, el complejo equilibrio entre Estado de derecho y Estado democrático en el que estos han estado descansando.
\end{abstract}

Palabras clave: Estado constitucional, Responsabilidad, Unión Europea, Democracia.

Abstract: This contribution aims to approach some of the different meanings of the principle of accountability of public authorities in the EU and in the Member States has. It begins with the essentiality of principle of accountability in the constitutional models and considers the separation process and the different nature assumed by political accountability and legal liability. The different logic that responds each explains how only after reaching the legal responsibility can be achieved political accountability within the EU. In particular, we study the principle of liability for violations of the EU law and how it can affect the correction model of situations created by the possible unconstitutionality of the law in the Member States. One definition of the principle of legal liability in the $E U$ is changing the concept of responsibility in the Member States, and thus the complex balance between rule of law and democratic state in which they have been underlying.

Key words: Constitutional State, Accountability, Liability, European Union, Democracy.

* El autor agradece a Juan Francisco SÁnchez Barrilao, Miguel Azpitarte SÁnChez y Tomás REQuena LóPEz que se tomen tanto gusto en discutir con el autor éstas y otras muchas cuestiones. 
Sumario: 1. Responsabilidad y Estado Constitucional.-2. Responsabilidad y derecho constitucional europeo.-3. Observaciones conclusivas (y no concluyentes).

\section{RESPONSABILIDAD Y ESTADO CONSTITUCIONAL}

El principio de responsabilidad en el Derecho constitucional es fruto de una larga historia (inacabada, como la misma historia).

Comienza con episodios sin responsabilidad, o responsabilidad sine die certus. Construcciones teóricas como el Derecho divino de los Reyes ${ }^{1}$ demuestra que el binomio «responsabilidad-poder» es admitido incluso cuando se trata de esquivarla. El brocardo «King do not wrong» no quiere decir que el Rey no esté sujeto a responsabilidad, sino que ésta sólo puede exigirse por aquél que es la fuente de todo poder. Dado que sus potestades no emanan de los súbditos sino de la voluntad divina, solo Dios estará en condiciones de poder controlar su ejercicio.

Con el Estado constitucional la responsabilidad se afirma como principio definitorio ${ }^{2}$. El poder ya no emana de una esfera inencontrable sino que corresponde a diferentes órganos que se han atribuido tras cruentos episodios la capacidad de ejercerlo. De esta forma se traba entre ellos un conjunto de relaciones paritarias (la delimitación de ámbitos competenciales inmunes) y desiguales. Efectivamente, se suele plantear que en el inicio del Estado constitucional hay una pugna de legitimidades: la del monarca y la de los órganos representativos; la de los Parlamentos y la del Poder Judicial (gubernaculum vs iurisdictio ${ }^{3}$ ); la de los órganos representativos y el propio pueblo (Cfr. la Septennial $\mathrm{Act}^{4}$ ). Esta pugna de legitimidades se va resolviendo de diferente forma en cada momento histórico y, en función de la posición constitucional que cada órgano llegue a alcanzar, es posible trabar una cadena de responsabilidades. El órgano con más legitimación de acuerdo con el principio que dé origen al ordenamiento atribuye poder a otro y éste le debe dar cuentas del ejercicio del poder que el primero le ha derivado. La responsabilidad es, así, directamente dependiente del concepto de soberanía (esencial hasta la Segunda guerra mundial y seguramente necesitado de una recuperación en la actualidad).

La responsabilidad plantea desde el primer momento la dificultad de precisar el parámetro para verificar si el sometido a la misma ha actuado correc-

\footnotetext{
${ }^{1}$ FIGGIS, J. N., El derecho divino de los reyes y tres ensayos adicionales, FCE, México, 1942.

${ }^{2}$ Es más, como me fue apuntado por el colega Miguel AzPITARTE, la propia decapitación del Rey puede entenderse como la forma inaugural y más extrema de la responsabilidad política.

${ }^{3}$ McIlwain, C. H., Constitucionalismo antiguo y moderno, CEC, Madrid, 1991.

${ }^{4}$ Mateucci, N., Organización del poder y libertad. Historia del constitucionalismo moderno, Trotta, Madrid, 1998. Véanse especialmente pp. 143-151.
} 
tamente. Así surge la diferencia esencial entre responsabilidad política y responsabilidad jurídica. Lógico es que surgiera primero la responsabilidad jurídica. Es menor, desde el punto de vista de su entidad y de su repercusión, en la medida en que sólo nace en determinados supuestos prefijados por la norma. La responsabilidad política presume una prelación de legitimidades mucho más clara en la medida en que el parámetro de control es predeterminado por aquél que hace valer la responsabilidad ante el responsable.

Una idea que está presente es que la responsabilidad será mayor cuanto menor sea la relevancia del órgano que ejerza el poder. Así los modelos democráticos siguen una pauta en la que la responsabilidad es muy alta en el caso de la administración, menor en el caso del Gobierno, prácticamente inexistente por lo que se refiere al Parlamento e inconcebible en lo que atañe al titular de la soberanía: el Pueblo.

Tras esta apretada síntesis estamos en condiciones de plantear la relevancia actual del principio de responsabilidad en un marco constitucional absolutamente complejo, indiscutiblemente de crisis, en el que, sostengo, vuelve a reabrirse una pugna de legitimidades. Esta pugna es, en buena medida, la eterna entre el Estado de derecho y la democracia sin soslayar en absoluto la no menos intrínseca tensión territorial entre entidades autónomas. Son precisamente las pretensiones no necesariamente armónicas de diferentes criterios de legitimación las que creo que constituyen la razón última de la enorme anfibología que tiene tras de sí en la actualidad el principio de responsabilidad ${ }^{5}$. En una tipología meramente ejemplificativa y que sólo se va a detener en algunas de las formas de responsabilidad de las que nos vamos a ocupar en estas reflexiones, según quien lo alegue y cuál sea el parámetro de control esgrimido, nos encontraremos con un principio de responsabilidad política capaz de aportar un nuevo concepto de representación; con un principio de responsabilidad jurídica concebido al servicio de la protección del ordenamiento europeo frente a su infracción; o con un principio de responsabilidad jurídica al servicio de la garantía de la Constitución (toda o parte de ella) como norma jurídica suprema.

Buena parte de esta anfibología se hace reconocible tras la Segunda Guerra Mundial, período en el que asistimos a una conceptualización del principio de responsabilidad que presenta notas especiales.

En primer lugar, afirmado el fin de la soberanía ${ }^{6}$, de la parlamentaria, e incluso de la popular (véanse los intentos de limitar el concepto de poder constituyente), la responsabilidad viene a operar como uno de esos principios con los que apoyar la configuración jurídica de la muerte del soberano. En espe-

${ }^{5}$ Cfr. el muy interesante trabajo de Gomes Canotilho, J. J., «Principios y "nuevos constitucionalismos". El problema de los nuevos principios», en Revista de Derecho Constitucional Europeo, Granada núm. 14, 2010.

${ }^{6}$ KrIELE, M., Introducción a la Teoría del Estado. Fundamentos históricos de la legitimidad del Estado constitucional democrático, Depalma, Buenos Aires, 1980. 
cial, la idea de que en el Estado constitucional no hay poderes sino competencias, esto es, capacidades de actuación previamente delimitadas por normas jurídicas, nos lleva a una evidente apogeo de la idea de Estado de Derecho y de la responsabilidad jurídica como uno de los instrumentos para que lo jurídico se plantee en ocasiones como única clave de bóveda de todo el sistema. Efectivamente, el derecho se convierte en el parámetro para poder deducir responsabilidad: las constituciones se configuran como norma y aquella ley que la contraríe será expulsada del ordenamiento jurídico; la administración está sometida a la ley e incurrirá en responsabilidad si no la observa; hasta el juez está sometido a instrumentos que aseguren el correcto ejercicio de la función jurisdiccional.

Además, el surgimiento de organizaciones como las Comunidades Europeas hace irrumpir otras formas de responsabilidad inéditas. Los Estados miembros son responsables por los incumplimientos del derecho comunitario. En su origen este principio toma cuerpo en el Recurso por Incumplimiento ante el Tribunal de Justicia pero posteriormente llega un mecanismo mucho más incisivo: la responsabilidad patrimonial de los poderes públicos estatales por incumplimiento del Derecho comunitario ${ }^{7}$. Ya no existe la soberanía tampoco en el orden internacional (puede que tampoco exista lo político) porque el orden internacional deja de serlo (en lo que toca al espacio jurídico compartido por los Estados miembros). La responsabilidad en este ámbito nace y se desarrolla en un contexto sistemático provocado por la conflictualidad natural de las relaciones entre ordenamientos que se pretenden exclusivos en sus respectivos ámbitos competenciales.

Frente a todas estas formas de responsabilidad jurídica, la responsabilidad política se ve sometida a serias dificultades para asegurar su subsistencia. Para empezar, el parlamentarismo racionalizado (MIRKINE) hace que los instrumentos creados para actuarla (Moción de Censura y Cuestión de Confianza en el ordenamiento español) no puedan prácticamente nunca suponer el cese del Gobierno. Esto ha llevado a hablar de una responsabilidad política difusa ${ }^{8}$ en lo que no es sino un intento de seguir manteniendo el concepto pese a la devaluación de su contenido. De otra parte, atrapados, como estamos, en una teoría de la representación ${ }^{9}$ de raigambre absolutamente clásica no es posible articular mecanismos que permitan que los ciudadanos puedan exigir el cese del representante cuando estimen que ya no les representa. La responsabilidad política, la que intenta derivar conse-

\footnotetext{
${ }^{7}$ Bien planteado el origen y la evolución del principio hasta llegar a la esencial doctrina KÖBLER en MARTín RodríGUEZ. P., «La responsabilidad del Estado por actos judiciales en Derecho comunitario», Revista de Derecho Comunitario Europeo, Madrid no 19, 2004.

${ }^{8}$ Rescigno, G. U., La responsabilità política, Giuffrè, Milán, 1967.

${ }^{9}$ Cfr., por todas, la STC 10/1983.Cfr. Garrorena Morales, A., Representación política y Constitución democrática (Hacia una revisión crítica de la teoría de la representación), Civitas, Madrid, 1991.
} 
cuencias cuando un órgano no se atiene al programa que se ha comprometido a cumplir con el poderdante, no ocupa una posición definitoria en nuestro sistema. Queda reducida al otorgamiento de la confianza y a su retirada en el momento electora ${ }^{10}$. No tenemos una teoría de la soberanía a base de negar que este concepto exista. Resta añadir que no se sabe cómo es posible que tengamos un concepto de democracia si hurtamos el debate sobre la soberanía.

De otra parte, las dinámicas de las dos instituciones, responsabilidad jurídica y responsabilidad política, son absolutamente disímiles en el sentido de que, mientras la primera busca la adecuación a una norma previa y por tanto la consolidación del estado de cosas existente (la seguridad), la segunda supone establecer una cadena de legitimidades que en última instancia tiene como fin al soberano: el Pueblo. En definitiva, los horizontes que se abren con el ejercicio de la responsabilidad política son mucho más abiertos y no se limitan a la mera reparación de los daños causados por la inapropiada conducta del órgano controlado ${ }^{11}$. Frente a la seguridad de la responsabilidad jurídica, la inseguridad de la responsabilidad política. Frente a la estabilidad, el cambio. Se entiende, así, que el concepto que galvaniza mejor todos los intentos de reducción de los mecanismos para actuar la responsabilidad política sea el de «estabilidad». Y se entiende el sentido de no admitir forma de responsabilidad alguna cuando se trata de blindar la existencia de ciertas instituciones (como es el caso de la Corona en el ordenamiento constitucional español) más allá de operar como argumentos supuestamente justificativos la improcedencia de exigir responsabilidad a quien no tiene libertad y la traslación de la responsabilidad al refrendante (art. 64).

${ }^{10}$ Éste es a mi juicio, uno de los factores que han aflorado en los movimientos sociales como el 15-M. El «No nos representan» se presenta como un eslogan ampliamente compartido porque el vínculo de dependencia que supone la responsabilidad de los cargos públicos respecto del titular de la soberanía aparece completamente desvaído. Por ello, sería necesario expandir el concepto de responsabilidad política; ampliar su contenido subjetivo, objetivo y temporal. Toca formular propuestas en este sentido. Sobre el 15-M, me remito a mi trabajo «El 15-M desde la óptica del socialismo democrático», en $E l$ cronista del Estado social y democrático de derecho, junio 2012.

${ }^{11}$ Pueden leerse en este sentido las siguientes palabras de Rafael Argullol en el artículo titulado «Farsa y delirio» (El País, 16 de septiembre de 2012): «Pues si, en efecto, conocemos a los autores, a los responsables de lo que se está escenificando, en una farsa que raya el delirio, entonces hay que desatar los mecanismos de la catarsis y exigir responsabilidades caiga quien caiga. En una democracia los actores son también los autores. Nadie puede alegar que únicamente participaba ficticiamente en la representación. Pero entonces las consecuencias son drásticas y, eliminados los dioses, el juicio de los hombres debería ser implacable para llegar al fondo de lo ocurrido. Esto es arriesgado y da miedo porque supone un ejercicio de crítica y autocrítica que, acostumbrados a ver la vida colectiva como una farsa, tal vez ya no estemos en condiciones de realizar»». 


\section{RESPONSABILIDAD Y DERECHO CONSTITUCIONAL EUROPEO}

Así las cosas, respondiendo la responsabilidad política a elementos políticos y la responsabilidad jurídica a la «neutralidad» de la norma no es extraño que la Unión Europea haya comenzado por la segunda. La Unión Europea como una comunidad de derecho; la Unión Europea como portadora de un ordenamiento que requiere ser observado por las instituciones de la misma Unión y por los Estados. Todas estas proclamas encuentran su correlato perfecto en FRANCOVICH ${ }^{12}$. Es decir, antes de que hubiera referencias a que el Presidente de la Comisión tenía que tener vínculos con el Parlamento elegido por el Pueblo de los Estados miembros; antes de cualquier forma de moción de censura, ya tenemos un principio que no está en los tratados sino que es inherente a ellos ${ }^{13}$ a partir del cual el ciudadano de cualquier estado de la Unión puede obtener una compensación económica si se le ha producido un daño como consecuencia de una infracción del derecho comunitario. La prioridad temporal de esta forma de responsabilidad demuestra una prioridad teleológica: la comunidad de derecho debe preceder a la Comunidad política. El derecho acercará a los Estados y no será la comunidad política la que propiciará un derecho común, de contenido político, alumbrado tras un proceso plenamente democrático de elección de representantes que en un marco de diálogo abierto solventen las diferencias ideológicas. La institución de la responsabilidad patrimonial por incumplimiento del derecho comunitario adquiere así un valor enorme $\mathrm{e}^{14}$ como instrumento de salvaguarda de la primacía y la eficacia del derecho europeo en la medida en que coloca también al particular como aliado del derecho europeo frente a la infracción de su estado.

Aquí hemos avanzado un paso más. La responsabilidad jurídica de la que ahora hablamos es la responsabilidad patrimonial y los que están sometidos a ella son los Estados. Es más, cualquier órgano del Estado (poder legislativo, poder ejecutivo y poder judicial) está sometido por la institución de la responsabilidad patrimonial cuando cause daños evaluables económicamente a consecuencia de la inobservancia del derecho europeo. El procedimiento para exigir tal responsabilidad es el que tenga establecido cada estado considerándose que no puede haber ninguna traba para quien pretenda plantear una demanda de responsabilidad por este concepto respecto de quien alegue una violación del derecho interno. De esta forma resulta que el ordenamiento constitucional español (y el de otros estados miembros) recibe un extraordinario impulso que dirige el principio de responsabilidad hacia confines apenas antes explorados.

En primer lugar, hace que la responsabilidad patrimonial pase a tener contenido constitucional y no puramente administrativo. Efectivamente hasta este

${ }^{12}$ As. C-6/90 y C-9/90.

${ }^{13}$ La inherencia, como es fácil de señalar, no está tan visible como la nariz en nuestras caras, utilizando la expresión de un clásico de la literatura y el cine «políticos»: El Mago de Oz. Cfr. críticamente Martín, P., op. cit., p. 830.

${ }^{14}$ Así es reconocido como un principio general del derecho europeo. Cfr., por ejemplo, Chiтı, M., Derecho administrativo europeo, Marcial Pons, Madrid, 2002, pp. 92-98. 
momento sólo la responsabilidad patrimonial de la administración estaba bien acabada en nuestro modelo constitucional en sentido material ${ }^{15}$, lo que obliga a remitirse a ésta como modelo de reparación de los daños causados ${ }^{16}$. A partir de ahora la responsabilidad patrimonial puede exigirse también cuando el legislador no transponga una directiva, y considerar patrimonialmente responsable al legislador tiene un contenido constitucional evidente, es un tema de raigambre absolutamente constitucional, porque tocan en él muchos extremos definitorios de principios contenidos en nuestra Norma Fundamental y, sobre todo, porque se da una nueva dimensión a elementos nucleares de nuestra estructura jurídico política tales como el sistema de fuentes, la capacidad de conformación de la realidad de los órganos productores de la ley, la capacidad del Tribunal Constitucional para determinar los efectos de sus fallos. Es, por tanto, un instituto que se separa de la responsabilidad patrimonial de la administración con la que solo comparte la idea de un daño que el poder público irroga a un ciudadano ${ }^{17}$.

En segundo término, tal admisión de la responsabilidad patrimonial, cuando alcanza al del legislador, por incumplimiento del derecho europeo exige que reordenemos de forma pareja nuestro modelo de corrección de la inconstitucionalidad de las leyes. Por decirlo con más claridad: que una ley interna pueda dar lugar a responsabilidad patrimonial por incumplimiento de una norma de otro ordenamiento sólo puede producirse porque la norma constitucional acepte tal opción (en nuestro caso a través del artículo $93^{18}$ ) pero de la misma manera que la Constitución Española no habilita que a través del derecho de la Unión se traspasen los contralímites ${ }^{19}$ no puede admitir que la respuesta a un ordenamiento derivado de la Constitución sea más garantista que la respuesta frente a la infracción del ordenamiento originario. En definitiva, lo que está en juego es la supremacía ordinamental ${ }^{20}$. De no hacerlo así estaríamos admitiendo que el derecho de la Unión merece mayor protección que el ordenamiento constitucional, manteniéndose incólume el principio de supremacía constitucional en el artículo 9.1 CE. Seguramente no es ajeno a este sentir el Tribunal Supremo cuando hace relativamente poco $^{21}$, y con una

${ }^{15}$ Señalo esto no sólo por su inserción constitucional clara en el artículo 106 CE sino por contar ya con un bagaje doctrinal y jurisprudencial bien aquilatado a partir de la LRJAE y la LEF.

${ }^{16}$ La cuestión aparece regulada en el artículo 139 de la ley 30/1992.

17 En el mismo sentido, Quintana LóPEZ, T., «La responsabilidad del Estado Legislador», RAP, núm. 135, 1994. p. 104.

${ }^{18}$ Planteando que por esta vía se da un contenido más amplio al artículo 9.3 CE.

${ }^{19}$ Declaración del Tribunal Constitucional 1/2004 (FJ 2).

${ }^{20}$ Podría plantearse si no es éste un mecanismo concebido esencialmente con ese fin: la protección del ordenamiento comunitario por esta vía (su principal misión, ya que la resarcitoria sólo sería asumida, si acaso, muy vicarialmente. Cfr. MARTín, P., op. cit.) puede suponer una subversión de los principios ordenadores de fuentes en los Estados miembros y especialmente que la supremacía constitucional de los Estados miembros (una gran resistencia al proceso de integración) descienda un escalón más.

${ }^{21}$ STS de 2 de junio de 2010 (Sala de lo Contencioso-Administrativo. Sección $1^{\text {a }}$ ). 
amplitud a mi juicio desmesurada, estima que la inconstitucionalidad del Decreto-Ley 5/2002 supone la obligación de reparar el daño causado aun cuando esta norma no fuera constitucional por razones materiales, sino formales ${ }^{22}$. Este último caso nos permite enfrentarnos a la cuestión de cuáles deben ser los principios para articular un sistema de responsabilidad patrimonial del legislador ${ }^{23}$ en el derecho interno. Hemos deducido su existencia a partir de una interpretación sistemática de la misma Constitución. Ahora debemos ver en qué casos opera, para lo cual podremos encontrar argumentos del derecho que lo hizo nacer. El punto de partida es que no es posible admitir el principio con tal amplitud que se disuada a la ley de actuar. Así es señalado tanto por la doctrina nacional ${ }^{24}$ como por la europea ${ }^{25}$. En una democracia lo político es esencial. No es posible democracia sin política y ello significa que no podemos soslayar en modo alguno que la ley es el resultado de un proceso en el que la mayoría coyunturalmente victoriosa en el parlamento evalúa las consecuencias de sus acciones y decide el futuro común adoptando una regla que, a la par que beneficia a algunos, perjudica a otros. No aceptar este principio ${ }^{26}$ equivale a concebir el Estado como vinculado al mantenimiento de la situación preexistente; la idea de que se han de conservar las situaciones de partida; afirmar que se puede hacer, pero no deshacer ${ }^{27}$. Por tanto, el principio de res-

${ }^{22}$ En concreto, en el caso en cuestión se concede la indemnización solicitada por el recurrente sobre la base de que el perjuicio económico que se vio obligado a soportar fue causado por un Decreto-ley (concretamente el Decreto-ley 5/2002) que fue declarado contrario a la Constitución por el Tribunal Constitucional por no acreditar suficientemente la concurrencia de la extraordinaria y urgente necesidad, que es presupuesto habilitante para poder dictar esta fuente con valor de ley (STC 68/2007).

${ }^{23}$ Que junto con el supuesto de la responsabilidad del juez es el único que presenta un desafío en nuestro modelo constitucional.

${ }^{24} \mathrm{El}$ amplio margen del legislador es una constante en la doctrina constitucional. Cfr., por ejemplo, la STC 128/2009 (FJ 3) para acotar el ámbito de aplicación del principio de interdicción de la arbitrariedad del legislador.

${ }^{25}$ Conclusiones del Abogado General Miguel Poiares Maduro en los Asuntos C-120/06 P y C-121/06 P. Parágrafo 70: «Las reticencias manifestadas por el Consejo y por la Comisión a que se consagre un principio de responsabilidad objetiva de la Comunidad son comprensibles. No debe pender sobre el ejercicio de la actividad legislativa y administrativa, por obra del establecimiento de un mecanismo de responsabilidad demasiado generoso, una amenaza que pudiera inhibir el propio ejercicio de esa actividad.

${ }^{26}$ Que es lo que esté detrás de la enorme impugnación que realiza GARCÍA DE ENTERRÍA, a la construcción de la responsabilidad del Estado-Legislador. Cfr. en especial GARCÍA DE ENTERRÍA, E., «El principio de protección de la confianza legítima como supuesto título justificativo de la responsabilidad patrimonial del Estado Legislador», RAP, núm. 159, 2002; y «El principio de "la responsabilidad de los poderes públicos" según el artículo 9.3 de la Constitución y la responsabilidad patrimonial del Estado legislador», REDC, $\mathrm{n}^{\circ} 67$.

${ }^{27}$ Realmente detrás de esta pugna están los dos conceptos que fundan los modelos jurídico-políticos occidentales: el liberalismo y la democracia. Como el liberalismo supone básicamente el establecimiento de controles al poder que preserven la libertad individual deriva en una teoría que cifra en los límites a la acción estatal su principal activo. En 
ponsabilidad del Legislador nunca podría afirmarse con este contenido. Una forma de comprobar si se produce esa llamada atrofia de la ley es examinar su alcance a la luz de la confianza pública ${ }^{28}$. Si la ley tiene una conexión considerable con parte del programa político que los representantes tienen que defender en el Parlamento de poco valdrá plantear el principio de protección del principio de confianza legítima para amparar la responsabilidad patrimonial del Legislador. Los que aquí rivalizarían sería el mismo principio democrático y el de protección de la confianza de los particulares reconocido en el artículo 3 de la LPA, lucha totalmente desigual. Observar la especialidad de la posición de la ley para plantear el modelo de corrección de los daños a los que eventualmente pueda dar lugar tiene mucho en común con la doctrina del Tribunal de Justicia de la Unión Europea que exige para dar lugar a indemnización que la violación del derecho europeo esté «suficientemente caracterizada $»^{29}$. De otro lado, debemos de distinguir entre dos situaciones que han dado lugar en nuestro país a pronunciamientos jurisdiccionales divergentes ${ }^{30}$. Me refiero a la diferencia entre que la ley que cause el daño sea constitucional o inconstitucional. En el primero de los casos entiendo que la constitucionalidad de una ley no obsta para que de lugar a responsabilidad patrimonial del legislador en muy contados y cualificados casos: 1) De acuerdo con una interpretación muy estricta del principio de sacrificio especial ${ }^{31}$ y 2) cuando

cambio, el postulado democrático conduce a la acción, a la transformación porque de la legitimación democrática del poder la presunción más inmediata es la de la bondad de las medidas adoptadas en beneficio del titular de la soberanía. Como dice HAYEK, F., en Los fundamentos de la libertad (Unión Editorial, Madrid, 1978, p. 143) para el liberalismo la ley puede no ser buena. Para la democracia, la ley es buena. Una manera de armonizar estas tendencias es el propio constitucionalismo, mezcla de acción y límite, apoderamiento y control, ley y control de la ley con arreglo a los postulados constitucionales. Un nuevo reequilibrio estaría en entender que la ley debe transformar sin herir la esfera patrimonial de las personas (en su teoría más extrema, sin herir, incluso, las expectativas patrimoniales de los individuos).

${ }^{28}$ GARCÍA DE ENTERRÍA, «El principio de...», op. cit., p. 181 siguiendo a MAURER.

${ }^{29}$ En Köbler (asunto C-224/01) eso permite al Tribunal de Justicia hacer las oportunas matizaciones sobre el margen que se ha de conceder al Poder judicial.

${ }^{30}$ Cfr. Galán Vioque, R., «De la teoría a la realidad de la responsabilidad del Estado legislador», RAP, núm. 115, 2001; y AHUMADA RUIZ, M. A., «Responsabilidad patrimonial del Estado por las leyes inconstitucionales (o el derecho a no ser perjudicado por una ley inconstitucional) », REDC, $\mathrm{n}^{\circ} .62,2001$.

${ }^{31}$ «Consagrada en el artículo 9-3 de la Constitución la responsabilidad de todos los Poderes Públicos, sin excepción alguna, resulta evidente que cuando el acto de aplicación de una norma, aun procedente del Poder Legislativo, supone para sus concretos destinatarios un sacrificio patrimonial que merezca el calificativo de especial, en comparación del que puede derivarse para el resto de la colectividad, el principio constitucional de la igualdad ante las cargas públicas impone la obligación del Estado de asumir el resarcimiento de las ablaciones patrimoniales producidas por tal norma y el acto de su aplicación, salvo que la propia norma, por preferentes razones de interés público, excluya expresamente la indemnización, cuya cuantía, de no concurrir tal excepción, debe ser suficiente para cubrir el perjuicio efectivamente causado». FJ $3^{\circ}$. STS 17 de noviembre de 1987 (Sala de lo Contencioso-Administrativo. Sección Pleno). 
quepa corroborar también muy excepcionalmente una quiebra del principio de confianza legítima, no en el sentido de sentirse defraudado en expectativas generales, sino cuando un viraje completamente súbito del legislador con respecto a su conducta de fomento anterior hubiera determinado un quebranto económico indiscutible e individualizado. El principio de confianza legítima aparecería así no como legitimador de la existencia del principio de responsabilidad del Estado-Legislador (que es lo que impugna ENTERRÍA) sino como un principio que permite precisar el alcance del principio deducido conforme a la Constitución. En estos dos casos es posible obtener la indemnización sin que se resientan los principios estructurales de nuestra Constitución: no se altera la confianza política, ni la posición del Parlamento. Simplemente aparece la responsabilidad patrimonial del legislador como un mecanismo excepcional de corregir efectos no directamente deseados por las leyes.

Por lo que se refiere a la responsabilidad por leyes inconstitucionales, es más controvertida que la anterior. Mientras unos se dirigen a la sentencia del Tribunal Constitucional como moduladora, otros la encuentran constreñida por la cadena inconstitucionalidad-indemnización, que viene a deducirse de una interpretación sistemática general del ordenamiento. Hay quienes, en cambio, erigen otros principios derivados de una cierta jerarquización en los perjuicios causados: si estos recaen sobre los derechos materialmente protegidos por la Constitución, la indemnización ha de imponerse. Si no son estos los afectados, queda un margen de discreción a colmar de la misma forma que si la fuente enjuiciada fuese constitucional. Mi juicio es más cercano a esta última postura en cuanto que reconoce que, al menos en determinados casos, la inconstitucionalidad de la ley supone el derecho a indemnización. En efecto, reconocido que el principio de responsabilidad de los poderes públicos alcanza también, en su formulación actual, al legislador, los perjuicios que éste cause a resultas de una actuación contraria a la Constitución no deben quedar sin cobertura. Y ciertamente no nos podemos olvidar del más valor de los derechos fundamentales en el sistema constitucional. La ley que los lesione debe sufrir las consecuencias que se marcan para las sentencias estimatorias de amparo: la declaración de nulidad de la decisión ${ }^{32}$, y el restablecimiento

${ }^{32}$ Aquí sí con un contenido bastante clásico como señala PÉREZ TrEMPS, «parece que la lesión de derechos fundamentales apreciada en amparo comporta un vicio de nulidad radical, que, como ya se ha apuntado, implica, como principio, que el acto carezca de efecto jurídico alguno, tal y como legislativamente prevén distintas normas al establecer los efectos de la nulidad de los actos contrarios a los derechos fundamentales. A partir de ese principio, los efectos de la nulidad podrán modularse por el Tribunal Constitucional atendiendo a la presencia de otros bienes jurídicamente relevantes y siempre y cuando dicha modulación no prive al recurso de amparo de su función reparadora» (las cursivas son mías). Cfr. Pérez Tremps P., «Comentario al artículo 55 LOTC», en Requejo Pagés, J. L., (coord.), Comentarios a la Ley Orgánica del Tribunal Constitucional, BOE, Madrid, 2001, p. 862 . 
de la integridad de su derecho, (Art. 55 LOTC) integridad que difícilmente podrá alcanzarse si hay daños patrimoniales que no se indemnizan.

Así, en tercer lugar, la responsabilidad patrimonial por incumplimiento del Derecho europeo al adquirir naturaleza constitucional en el sentido que acabamos de mostrar tiene en esta ocasión la virtualidad de incorporar también a esta rama del derecho, con todo su vigor, la cuestión de los daños. Efectivamente, responder patrimonialmente es hacer frente a los daños. Introducir la responsabilidad patrimonial en el modelo de corrección de la inconstitucionalidad es contar con los daños. Y en este sentido puede apreciarse un completo cambio respecto de la situación con la que han actuado los operadores jurídicos (especialmente el Tribunal Constitucional) a partir de una interpretación prácticamente incuestionada tanto de la Constitución como especialmente de la Ley Orgánica del Tribunal Constitucional que, en el ámbito del recurso de amparo, y por tanto en el marco de la protección jurisdiccional excepcional de los derechos fundamentales, entendía que el artículo 55 de esta ley impedía que el Tribunal otorgara indemnizaciones ${ }^{33}$. A nuestro entender,

${ }^{33}$ Como hipótesis, podemos sugerir que entre las razones para no considerar posible la concesión de indemnizaciones por el TC cuando se aprecia la lesión de un derecho fundamental están también dos ideas directamente relacionadas con el origen y la naturaleza de los derechos fundamentales.

La razón referente al origen pasaría por admitir que el espíritu ilustrado que concibió la idea de los derechos confiaba en que, una vez admitida la idea y lo que está significaba, la lesión no tuviera lugar. Cuando, en definitiva, los derechos se abrieron paso en el horizonte intelectual y la burguesía alcanzó el poder que le permitió que el horizonte se asemejara a los principios que postulaba, la hipótesis de la lesión era como la de la enfermedad en un cuerpo sano: una contingencia altamente improbable. Otro tanto ocurría con la renuncia de los derechos (sin distinguir en este punto entre renunciar a la titularidad o a su ejercicio; ambas eran aberraciones, aunque de desigual grado). Las dos eran consideradas ontológicamente patologías y no son los momentos de alumbramiento los óptimos para anticipar cuidados paliativos. Esta idea se enraizó de tal manera en la estructura comprehensiva del constitucionalismo que ambas cuestiones, la responsabilidad patrimonial por lesión del derecho fundamental y la posibilidad de que un titular de un derecho, que ha nacido con él, pueda por propia voluntad renunciar al mismo, siguen siendo retos intelectuales de difícil resolución para el constitucionalismo contemporáneo.

La cuestión que se remite a la naturaleza de los derechos tiene que ver con que estos se concibieron al margen del contrato, de los contratos (el contrato social era en verdad una ficción, nada parecido a un contrato, en el que las partes están bien definidas así como las obligaciones recíprocas y las posibilidades de rescisión del mismo. El contrato social para todos los que lo han mantenido ha sido siempre una hipótesis conceptual que echó mano del referente más cercano a falta de otro, que por inédito, necesitaría de mayor legitimación), en la medida en que los derechos se concedían al hombre por su naturaleza, por su cualidad de hombre. Los derechos, al ser denominados fundamentales, fueron el producto de una operación de secesión; una creación nueva por elevación que los separaba de derechos como el de retracto (por ejemplo) y de ahí que difícilmente tuvieran acogida los elementos propios del derecho de daños como la responsabilidad contractual o la aquiliana. De alguna forma admitir la indemnización cuando se viola el artículo 1 de la Virginia Bill of Rights: «all men are by nature equally free» puede equivaler a privarlo de sustancia, de 
por el contrario, es una violación de la Constitución «suficientemente caracterizada» aquella que supone una lesión de un derecho fundamental, y cuando

su capacidad generadora, sumirlo de nuevo en la relativa «inanidad» de los derechos ordinarios, trivializarlo, en definitiva.

Otro elemento relativo a la naturaleza atribuida a los derechos fundamentales es el que pone el énfasis en que son una seña de identidad de una realidad que no se contenta con reconocer una situación favorable a ciertos sujetos. No, el nuevo modelo solo podía funcionar bajo condiciones de universalidad. Es indiscutiblemente individualista (pues hace a cada uno de los sujetos titulares de los derechos) pero general (en la medida en que sólo el ejercicio generalizado de la libertad puede desmontar las estructuras del Antiguo Régimen y llevar, de acuerdo con las nuevas doctrinas económicas, la prosperidad). Así las cosas, la lesión, al margen de la lesión del derecho de propiedad, no tenía contraprestación, en buena medida porque la violación de un derecho fundamental suponía una violación sufrida por la sociedad, y la dimensión colectiva, la afectación del nuevo orden creado, hacía que difícilmente encajará la reparación individual. De otra parte, los derechos habían reemplazado en el mundo laico a lo divino y de la misma manera que la ofensa a Dios no podía repararse pecuniariamente tampoco podría serlo la lesión a la libertad de expresión. La única forma posible de proceder cuando se consuma una lesión de un derecho fundamental es la restitución in natura y de ahí que sea el más sustancial de los pronunciamientos que todavía hoy leyes reguladoras de la jurisdicción constitucional como la española incluyen en los artículos dedicados al contenido de la sentencia que otorgue el amparo. En este sentido el supuesto que mejor ejemplifica este ideal de hacer como si nada hubiera ocurrido es el que permite la retroacción de la realidad al momento anterior al que se produjo la lesión. De esta forma el mundo vuelve al estado armónico anterior al caos desatado cuando lo informe (la lesión del derecho) tiene lugar. El modelo de reparación de las lesiones recaídas sobre la tutela judicial efectiva es el que en mejor medida se ajusta a este esquema. Si la no admisión de una prueba genera indefensión, se procede a determinar su admisibilidad y el juicio continúa.

Hoy, los dos presupuestos de lo que hemos hablado no concurren. El primero porque toda ingenuidad ha desaparecido. No estamos en ese momento iniciático en el que convocar a un principio equivale a verlo hecho realidad. La democracia constitucional aparece como un artilugio complejo en el que los derechos no se relacionan según un esquema binario: «reconocimiento constitucional-desarrollo legislativo coherente». Hoy en los derechos cabe ver un contenido absolutamente irrenunciable pero también una habilitación a actuar para alcanzar su desarrollo más completo (estoy pensando, por ejemplo, en la seguridad del artículo 17) que puede llevar al legislador a excederse y violar el contenido de otro derecho o libertad. Quiero señalar con ello que la violación de los derechos fundamentales no puede considerarse como antaño como una patología altamente improbable cuando asumes lo que los derechos significan en un contexto histórico abiertamente cambiante. De otra parte los derechos han alcanzado tal nivel de reconocimiento que su éxito ha generado un número de violaciones creciente (así la tutela judicial efectiva). En lo que atañe a la sacralización de los derechos, es preciso destacar que hoy la compensación a quien ha sido lesionado por un derecho fundamental no tiene que equipararse a una patrimonialización del mismo ni, en definitiva, puede suponer una involución en el sentido de entender que los hace parte de una relación exclusivamente económica o contractual. Hoy los derechos están tan afirmados, tan absolutamente vinculados al principio de dignidad humana (art. 10.1 CE y 1. De la LFB) que la concesión de una reparación económica puede operar como un mecanismo adicional para evitar lesiones posteriores. Por ello, los TC no deberían de mostrarse tan absolutamente reacios a la idea de que restablecer al recurrente en la integridad de su derecho exige conceder puntualmente una indemnización. 
tal lesión no permita el restablecimiento del recurrente en la integridad de su derecho y el daño reúna ciertas condiciones que permitan su indemnización, ésta debe formar parte sustancial de la respuesta del Tribunal Constitucional.

\section{OBSERVACIONES CONCLUSIVAS (Y NO CONCLUYENTES)}

En definitiva, la responsabilidad patrimonial del legislador es una nueva forma de responsabilidad que surge fundamentalmente por el influjo del Derecho europeo en su desarrollo jurisprudencial. Al afectar a fuentes y órganos de derecho interno obliga a reconstruir la unidad de los ordenamientos contando con las transformaciones operadas. Hay que volver a sistematizar el sistema de fuentes. Las operaciones que se llevan a cabo pues son de índole jurisprudencial y doctrinal lo que significa que ha habido un nuevo embridamiento de la ley sin el debate que debe ser preceptivo en una democracia ${ }^{34}$. Se corre con este principio el riesgo del inmovilismo, de un inmovilismo sancionado por el derecho que vendría a cerrar así un círculo impeditivo de la transformación sustancial ayudado por otros principios como el de seguridad jurídica, confianza legítima, buena fe, igualdad ente las cargas públicas o irretroactividad de las disposiciones restrictivas de derechos individuales. Esto es a nuestro juicio incuestionable ${ }^{35}$ y está relacionado, aunque no de forma

${ }^{34}$ En mi opinión, sobre esta cuestión tan nodal es totalmente inoportuno dar pábulo a la interpretación judicial en los términos vistos. No es posible que sean los jueces los que nos provean de un modelo de corrección de los efectos creados por leyes inconstitucionales. Nuestro sistema exige, al contrario, que semejante cuestión, de calado teórico enorme y de efectos prácticos no menos importantes, sea resuelta en el seno de un procedimiento como el legislativo en el que se ponderen los principios en juego que he tratado de exponer aquí. Ello supone la modificación en su caso de diferentes fuentes de rango legal. Claramente de la LPA, para hacer más explícito el sentido del principio, También claramente de la LOTC para clarificar por lo menos las relaciones, no necesariamente rígidas ni unívocas, entre inconstitucionalidad de una ley y efectos ex tunc o ex nunc. Lo que postulamos aquí es que no se puede hacer dejación de este tema como no era posible ad aeternum olvidar el tratamiento legislativo de los actos políticos. Los órganos definitorios de la política deben entrar a saco en una cuestión que puede dificultar que la hagan y los ciudadanos deben situarse al respecto. Cuando SANTAMARÍA PASTOR (La teoría de la responsabilidad del Estado Legislador, $\left.R A P, \mathrm{n}^{\circ} 68,1972\right)$ sostenía el carácter iconoclasta de la teoría nos pone sobre aviso también de que los iconos, por su carácter simbólico, no deben ser destruidos por quienes no tienen esa misión.

${ }^{35}$ Contrariamente a lo que piensa, por ejemplo, GALÁN («De la teoría a la realidad...», op. cit., p. 288) al manifestar que no es una cuestión con ribetes ideológicos, lo que deduce de que las diferentes opciones políticas que han gobernado en nuestro país no han mantenido ningún contencioso (antes al contrario) al respecto. Creemos que esto no le quita un ápice de sentido a lo que mantenemos y, en todo caso, a lo que nos lleva es a sospechar de la supuesta disparidad ideológica. Otro debate es el que trae a colación SANTAMARÍA PASTOR al final de su esclarecedor artículo escrito en una época en el que el análisis marxista todavía contaba y en que se discutía sobre si el mercado lograría alguna vez elevar definitivamente el nivel de vida de las clases proletarias. 
unidimensional, con otra suerte de deriva también comprobable en la actualidad y que aqueja a la mayoría de las democracias. Hablamos de una suerte de hipertrofia del concepto de Estado de Derecho que hace bascular sobre lo jurídico, y sobre todo, sobre lo jurídico en el momento aplicativo, la tabla de salvación de los conflictos sociales. En un período en el que se vitupera lo político y sus manifestaciones, desde el concepto de soberanía, a los partidos o los Parlamentos (cuestión que no nos es ajena del todo a los constitucionalistas, tan empeñados en el control del poder) las actuaciones que como la responsabilidad patrimonial del legislador erigen al juez en el centro de la corrección de los efectos perniciosos de la ley (esto es, de lo político) juegan a caballo ganador. El papel de la doctrina crítica, sin embargo, debe desvelar la madeja de transformaciones que su admisión indiscriminada podría suponer. Porque no sería poco el contrasentido de oponer una acepción sesgada del Estado de Derecho, (olvidadiza de que la legitimidad del juez es de ejercicio en cuanto aplicador de la ley elaborada por o con el concurso del órgano más representativo) al Estado democrático. Éste, no lo olvidemos se manifiesta en una estructura institucional en torno al parlamento como órgano central y a la ley como expresión más completa de la sociedad plural en tanto que fuente elaborada por un procedimiento transaccional y público y regido por la regla de las mayorías y el respeto de los derechos de las minorías. 